\title{
An analysis of regional climate model performance over the tropical Americas. Part II: simulating subseasonal variability of precipitation associated with ENSO forcing
}

\author{
By ETIENNE TOURIGNY and COLIN G. JONES ${ }^{*}, \dagger$, Université du Québec à Montréal, CRCMD Network, \\ Montréal, Canada
}

(Manuscript received 3 April 2008; in final form 28 November 2008)

\begin{abstract}
A B S TRACT
The El Niño/Southern Oscillation (ENSO) constitutes a major source of potential predictability in the tropics. The majority of past seasonal prediction studies have concentrated on precipitation anomalies at the seasonal mean timescale. However, fields such as agriculture and water resource management require higher time frequency forecasts of precipitation variability. Regional climate models (RCMs), with their increased resolution, may offer one means of improving general circulation model forecasts of higher time frequency precipitation variability.

Part I of this study evaluated the ability of the Rossby Centre regional atmospheric model (RCA), forced by analysed boundary conditions, to simulate seasonal mean precipitation anomalies over the tropical Americas associated with ENSO variability. In this paper the same integrations are analysed, with the focus now on precipitation anomalies at subseasonal (pentad) timescales.

RCA simulates the climatological annual cycle of pentad-mean precipitation intensity quite accurately. The timing of the rainy season (onset, demise and length) is well simulated, with biases generally of less than 2 weeks. Changes in the timing and duration of the rainy season, associated with ENSO forcing, are also well captured. Finally, pentad-mean rainfall intensity distributions are simulated quite accurately, as are shifts in these distributions associated with ENSO forcing.
\end{abstract}

\section{Introduction}

Regional climate models (RCMs) are increasingly being used in tropical regions to downscale global climate model (GCM) simulations of seasonal and interannual variability (Sun et al., 2006; Seth et al., 2007, and references therein). The increased resolution of RCMs, compared with GCMs, allows for a potentially more accurate simulation of regional climatic features, particularly those resulting from localized surface forcing or organized on small scales. Moreover, statistical or dynamical downscaling of GCM forecasts may improve the simulation of important meteorological variables at high time frequency (Goddard et al., 2001). The coupled ocean-atmosphere phenomenon, known as the El Niño/Southern Oscillation (ENSO), is the leading mode of interannual sea surface temperature (SST) variability in the

\footnotetext{
* Corresponding author. e-mail: colin.jones@smhi.se $\nmid$ Now at: SMHI, Rossby Centre, SE-601 76, Norrköping, Sweden. DOI: $10.1111 /$ j.1600-0870.2008.00387.x
}

tropics (Wang et al., 1999). It follows that RCMs, when forced by ENSO-related SST and large-scale atmospheric forcing, should show some skill in simulating seasonal and subseasonal precipitation anomalies in the tropics. In this work, we will analyse the ability of a RCM to represent subseasonal regional scale anomalies over Central and South America, occurring under El Niño and La Niña conditions, when the RCM is forced by observed SSTs and analysed lateral boundary conditions (LBC). As discussed in a companion paper (Tourigny and Jones, 2009), hereafter referred to as TJ2009a, this exercise should be viewed as a necessary first evaluation step, before the RCM is forced by boundary conditions derived from a free-running GCM.

El Niño conditions are associated with anomalous warm waters in the equatorial Central and East Pacific. This leads to an increase in deep convection in those regions and anomalous rainfall in other regions of the globe through various atmospheric and oceanic teleconnections (Alexander et al., 2002). La Niña conditions show largely converse behaviour, with cold SST anomalies and a reduction in convective activity in the equatorial Central and East Pacific. The SST and convection anomalies 
force identifiable seasonal mean precipitation anomalies over the tropical Americas. In TJ2009a, we assessed the ability of a RCM to downscale the large-scale signature of these anomalies at the seasonal mean timescale. In this paper, we extend this analysis to higher time frequency anomalies in precipitation over the tropical Americas. As in similar studies (Ropelewski and Halpert, 1987, 1996), we define composite years (0) and $(+)$, which represent the years during and after 'typical' ENSO events, with the peak of anomalous SST in the $\operatorname{OND}(0)$ season (i.e. October-December of year (0)).

A number of studies have identified interannual variability of the rainy season onset and demise over the tropical Americas associated with ENSO forcing. Enfield and Alfaro (1999) showed that over Central America, the rainy season onset is correlated with North Atlantic SSTs and that the demise of the rainy season is correlated with both North Atlantic and ENSO-related (East Pacific) SST variability. A warm East Pacific (El Niño conditions) is associated with an early demise of the rainy season in year (0) over Central America, consistent with dry conditions observed from July to October (0) (whereas La Niña conditions cause a late demise of the rainy season). As the rainy season over Central America extends from May to October and the ENSOrelated anomalies are from July to October $(0)$, it is clearly only the demise of the rainy season that is likely to be affected by ENSO variability.

El Niño conditions reduce sea level pressure (SLP) in the northern tropical Atlantic in winter $(+)$, weakening the easterly trade winds and causing a reduction in moisture convergence into the Amazon basin (Nobre and Shukla, 1996). This leads to decreased convection (Marengo, 1992; Marengo and Hastenrath, 1993) and a delay in the onset of the rainy season (and to a lesser extent an early demise; Liebmann and Marengo, 2001; Marengo et al., 2001) in the northern Amazon, whereas the converse is generally true for La Niña conditions. There is also evidence of tropical Atlantic SST variability, independent of ENSO forcing, influencing moisture transport into the Amazon (Fu et al., 2001, and references therein). Moreover, Liebmann and Marengo (2001) found that SST anomalies influence the timing of the rainy season but not the intensity of precipitation within the rainy season over the Amazon.

Regarding ENSO impacts on the intensity distribution of higher time frequency precipitation, Seth et al. (2004) have shown distinct changes in the intensity distribution of daily precipitation over the Amazon basin, between one El Niño year (1983) and a single La Niña year (1985). Specifically they found, for the period January-May (+), a shift in the distribution resulting in more frequent weak precipitation events and a reduction in the number of intense events. Rauscher et al. (2007) also found a shift towards more weak rainfall events during El Niño years and a converse shift towards more intense rainfall events during La Niña years over northeast Brazil. These two studies show that a dry seasonal anomaly comes about mainly from a reduction in the number of days with moderate to intense precipitation and an increase in the number of days with weak or no rainfall. The RCM used in these two studies (RegCM3) generally succeeded in simulating these intensity distribution changes.

In this work, we use the Rossby Centre regional atmospheric model (referred to as RCA) version 3 (Jones et al., 2004; Kjellström et al., 2005) to study the simulated variability of subseasonal precipitation over Central and South America, associated with ENSO-related variability. Part I of this study (TJ2009a) looked at regional-scale variability of precipitation associated with ENSO at seasonal mean timescales. We found that RCA was able to reproduce most of the seasonal climatological features of precipitation over the domain of study, as well as capturing the main observed anomalies related to ENSO SST forcing. Here, observed pentad-mean values of precipitation are used to evaluate the ability of RCA to simulate both the climatology and ENSO-related variability of pentad timescale precipitation using the following metrics: (1) the annual cycle of pentad-mean precipitation; (2) rainy season onset, demise and duration and (3) subseasonal (pentad) intensity distributions. Details of the various diagnostics metrics used in the model evaluation appear in both Section 2.2 and at the relevant results sections of the paper.

\section{Model configuration and analysis methods}

For details on model setup, experimental procedure and domain of analysis, the reader is refereed to TJ2009a. The regions analysed, shown in Fig. 1 of TJ2009a, are northern Mexico (MEX), Caribbean (CAR), Central America (CAM) and northern Amazon (NAMZ).

\subsection{Observations}

A study of precipitation anomalies at subseasonal timescales should ideally use daily or even subdaily precipitation observations. Reliable daily observations are scarce in Central America and the Caribbean, and gridded products are non-existent. South America on the contrary has a denser observation network, and a few gridded products are available. This study uses the 'Daily Precipitation Grids for South America' from Liebmann and Allured (2005), hereafter referred to as LASA. The current version (SA19) is available at a resolution of $1^{\circ}$ over land points with temporal coverage from January 1940 to August 2006. Liebmann and Allured have also prepared a similar data set (NA1) that covers the United States and parts of Mexico, with temporal coverage from January 1940 to December 2004. This data set is used over the MEX region of our domain and is referred to as LANA. Reanalysis products, such as the ERA-40 reanalysis (Uppala et al., 2005) from the European Centre for Medium-Range Weather Forecasts (ECMWF) and the NCEP/NCAR Reanalysis, offer subdaily precipitation estimates. These products, however, suffer from deficiencies in the tropics (such as an overestimate of rainfall intensity), which 
(a) CAR / CLIM

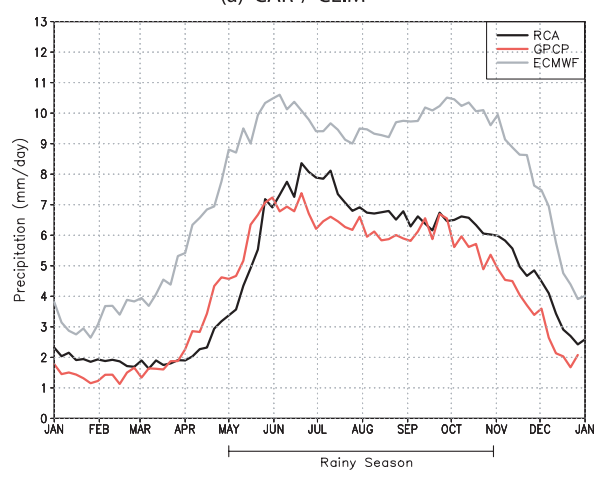

(c) NAMZ / CLIM

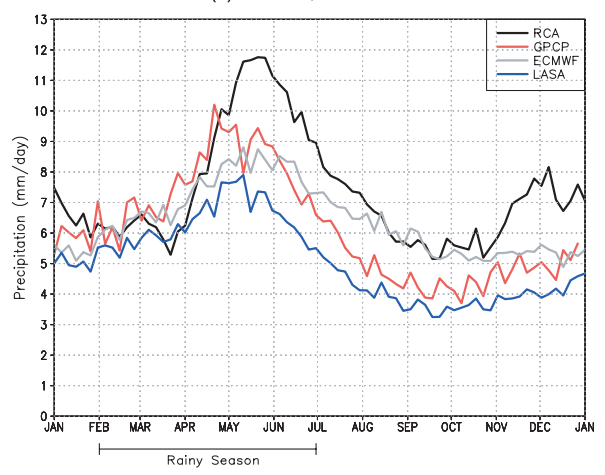

(e) CAR / NINOA

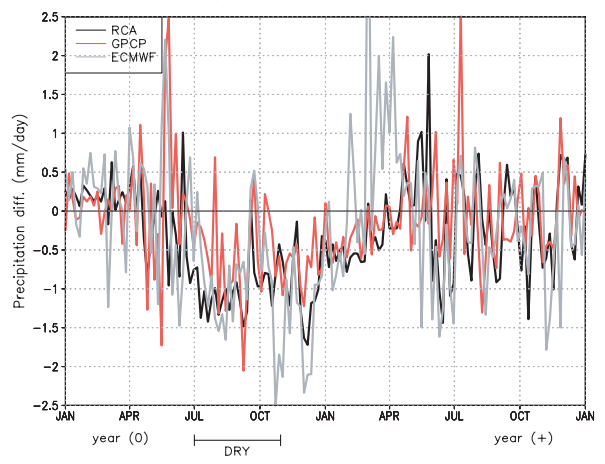

(b) CAM / CLIM

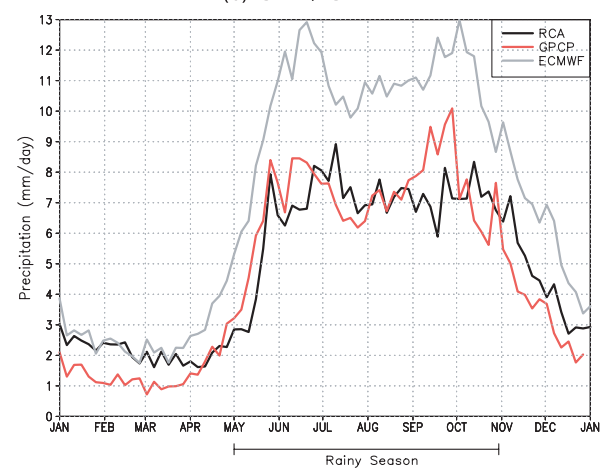

(d) MEX / CLIM

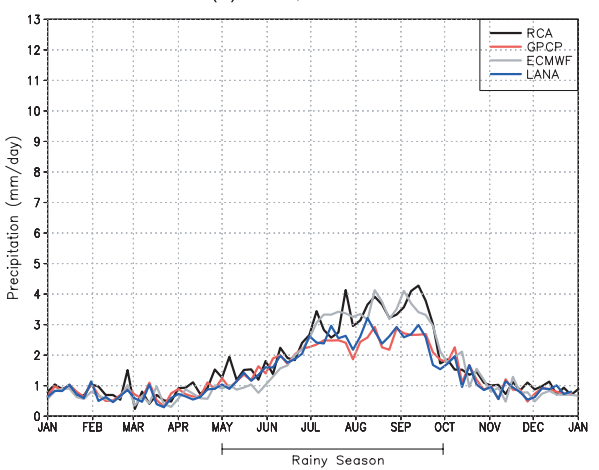

(f) NAMZ / NINOA

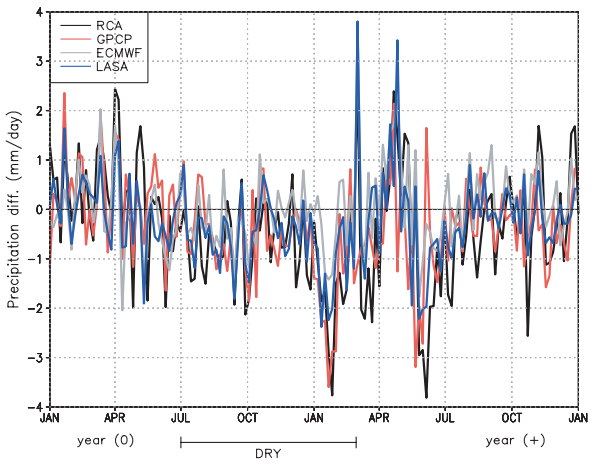

Fig. 1. Spatial mean climatological precipitation (top rows) and El Niño anomalies of precipitation (bottom row), annual cycle by region over land $\left(\mathrm{mm} \mathrm{d}^{-1}\right)$. The duration of the climatological rainy season and the typical period and impact (wet/dry) of ENSO variability are indicated for each region on the $x$-axis.

limit their use as an observational surrogate. To illustrate this we combine the ERA-40 reanalysis and ECMWF operational analysis daily data (from August 2002) into one data set, which we name ECMWF and use as a point of reference. A recent study by Ropelewski and Bell (2008) suggests that the gridded LASA data set is more suitable than reanalysis data (or even station data) for a study, such as ours, evaluating simulated shifts in daily rainfall over South America, associated with ENSO.

The scarcity of gridded daily observations over Central America and the Caribbean has forced us to turn to satellite-based pentad observations. We chose the GPCP pentad precipitation (hereafter referred to as GPCP), described by Xie et al. (2003).
The GPGP pentad data are at a relatively low resolution $\left(2.5^{\circ}\right)$ but covers a long time period (1979-present), allowing an evaluation of numerous ENSO events; hence it is used as the main observational data set in this study. Higher temporal and spatial resolution observations, such as the Tropical Rainfall Measuring Mission (TRMM) 3B42 product (Huffman et al., 2007) and GPCP 1DD (Huffman et al., 2001), respectively at $0.25^{\circ}$ and $1^{\circ}$ spatial resolution and three hourly and daily temporal resolution, would be better suited for RCM evaluation of subseasonal precipitation. Unfortunately these data sets are limited in temporal extent, available from 1998 and 1997, respectively, and therefore do not allow an extensive evaluation of simulated ENSO 
variability. We nevertheless use the TRMM 3B42 data set for the 1998-2004 period and compare it with GPCP and RCA, as well as a lower-resolution $\left(1^{\circ}\right)$ version of the RCA model (RCA1). This allows us to evaluate the potential added value of using a high-resolution RCM with respect to small-scale precipitation variability and also to assess the reliability of the low-resolution GPCP data set.

\subsection{Methods}

Our main emphasis is on the 1979-2004 period, during which the model is compared with GPCP and ECMWF in all regions, the LASA data set is also used over the NAMZ region, whereas LANA provides an additional observational constraint over the MEX region. Daily precipitation values are averaged at the pentad $(5 \mathrm{~d})$ timescale. In an effort to limit discrepancies due to differing resolutions, all observations and the model output are interpolated to a uniform $1^{\circ} \times 1^{\circ}$ grid, using bilinear interpolation. The method used to define the warm and cold ENSO events is based on SST anomalies over the Niño 3.4 region and is outlined in section 4.2 of TJ2009a. We choose only the strongest ENSO events (shown in Table 1 of TJ2009a) to obtain a clear anomaly signal.

Three diagnostic methods are used to assess the ability of RCA to simulate pentad timescale precipitation. First, we analyse the climatological annual cycle of pentad mean precipitation for the four regions of interest. We also study composites of El Niño and La Niña anomalous pentad mean precipitation as a function of the annual cycle. Second, we evaluate the model's ability to simulate the timing of the onset and demise of the rainy season in each region and any variability of these quantities associated with ENSO forcing. Third, we analyse the simulated pentad-mean precipitation intensity distribution for each region during their respective rainy seasons and spatially over the entire model domain. We evaluate both the climatological intensity distribution and shifts in this distribution during ENSO years.

For the spatially averaged climatologies and the ENSOrelated anomalies, grid box values of each of the variables are spatially averaged over each of the regions of interest for every year. We first calculate the climatological average of a given variable over all years (1979-2004). To evaluate the interannual variability associated with ENSO forcing, we calculate ENSO composites, which are the average of El Niño or La Niña years separately, considering years $(0)$ and $(+)$ of the ENSO events, as the atmospheric responses show a temporal evolution during a 'typical' ENSO event of 2 yr. The ENSO signal is easier to evaluate when the composites are given as anomalies or differences from climatology. The resulting metrics are thus defined as

$N I N O A=\overline{N I N O}-C L I M$,

$N I N A A=\overline{N I N A}-C L I M$, where $\overline{N I N O}$ and $\overline{N I N A}$ are the basic ENSO composite values of a given variable, CLIM is the climatological average of the same variable and NINOA and NINAA are the anomalies of the ENSO composites, with all values being at the pentad timescale.

\section{Results}

\subsection{Annual cycle of precipitation}

This section discusses the annual cycle of pentad-mean precipitation, with results from RCA, GPCP and ECMWF. Figs 1a-d shows the climatological average for all years of the study (19792004) for all four regions. On the $x$-axis of the climatological precipitation figures, we indicate the typical rainy season duration (rounded to the beginning of the month), as derived from the GPCP data in Table 1, which details the observed, climatological onset and demise dates of the rainy season by region. Details on the method for calculating these dates are given in Section 3.2. Figures 1e and $\mathrm{f}$ give the anomalous precipitation for the El Niño (NINOA) composites, expressed as absolute deviations from the climatology in $\mathrm{mm} \mathrm{d}^{-1}$, for regions CAR and NAMZ only. These regions contain the main anomalies associated with ENSO; for details concerning the other regions, refer to the seasonal mean anomalies outlined in TJ2009a. On the $x$-axis, we indicate the generally accepted time periods, within the annual cycle, of El Niño forced precipitation anomalies (dry/wet) with respect to each region (Ropelewski and Halpert, 1987, 1989, 1996). This is done to highlight when and where ENSO forced anomalies impact on the climatological rainy season. Similar results are given for all regions and both El Niño and La Niña composites in TJ2009a at monthly timescales.

The CAR region (Fig. 1a) has a distinctive rainy season from May to October (inclusive), which RCA captures quite accurately, with a wet bias of $\approx 1 \mathrm{~mm} \mathrm{~d}^{-1}$ throughout the rainy season and slight dry bias at the beginning. ECMWF shows a large wet bias over the Caribbean and Central America. In the CAM region (Fig. 1b), the model performance is quite accurate, except for a poor representation of the mid-summer drought (MSD; Small et al., 2007). The MSD is recognized as a drop in precipitation in July-August, followed by a second maximum peak in precipitation in September. RCA does show a slight drop in July, but fails to recover in September, exhibiting a dry bias. In TJ2009a, we showed that the basic dynamic and precipitation features of the MSD were simulated by RCA, but due to an incorrect spatial distribution and intensity of localized precipitation maxima and minima (mostly over the western Caribbean), the MSD does not appear in the simulated spatial averages over CAM at monthly timescales. Close inspection of pentad-mean values shows that the MSD is present in the RCA results, although with reduced amplitude compared to observations.

Over the NAMZ region (Fig. 1c) the rainy season is from February to June. Although RCA correctly simulates the 
Table 1. Climatological onset and demise (month-day) and length (d) of rainy season by region and changes (d) in the onset, demise and length for El Niño and La Niña years

\begin{tabular}{|c|c|c|c|c|c|c|c|c|c|c|}
\hline \multirow[b]{2}{*}{ Region } & \multirow[b]{2}{*}{ Data } & \multicolumn{3}{|c|}{ Climatology } & \multicolumn{3}{|c|}{ El Niño changes } & \multicolumn{3}{|c|}{ La Niña changes } \\
\hline & & Onset & Demise & Length & Onset & Demise & Length & Onset & Demise & Length \\
\hline \multirow{3}{*}{ CAR } & GPCP & $05-06$ & $11-02$ & 180 & 0 & -15 & -15 & -5 & +10 & +15 \\
\hline & ECMWF & $04-26$ & $10-18$ & 175 & 0 & -15 & -15 & -5 & +15 & +20 \\
\hline & RCA & $05-16$ & $11-02$ & 170 & +10 & -20 & -30 & -5 & +20 & +25 \\
\hline \multirow{3}{*}{ CAM } & GPCP & $05-21$ & $11-07$ & 170 & 0 & -5 & -5 & 0 & +10 & +10 \\
\hline & ECMWF & $05-11$ & $10-28$ & 170 & +5 & -10 & -15 & 0 & +15 & +15 \\
\hline & RCA & $05-31$ & $11-07$ & 160 & +10 & -15 & -25 & -10 & +10 & +20 \\
\hline \multirow{3}{*}{ NAMZ } & GPCP & $01-31$ & $07-10$ & 160 & +10 & -15 & -25 & -25 & +10 & +35 \\
\hline & ECMWF & $02-05$ & $07-15$ & 160 & 0 & 0 & 0 & -20 & +10 & +30 \\
\hline & LASA & $01-16$ & $06-30$ & 165 & +10 & -10 & -20 & -15 & +5 & +20 \\
\hline \multirow{5}{*}{ MEX } & RCA & $02-05$ & $07-20$ & 165 & +15 & -15 & -30 & -30 & +15 & +45 \\
\hline & GPCP & $05-11$ & $10-03$ & 145 & -15 & +5 & +20 & +10 & -15 & -25 \\
\hline & ECMWF & $05-16$ & $09-23$ & 130 & -10 & +5 & +15 & +10 & -30 & -40 \\
\hline & LANA & $05-11$ & $10-03$ & 145 & -15 & +5 & +20 & +10 & -10 & -20 \\
\hline & RCA & 05-01 & $09-13$ & 135 & -5 & +10 & +15 & +15 & -20 & -35 \\
\hline
\end{tabular}

beginning of the rainy season, there is a clear wet bias starting in May and extending through the year. RCA also exhibits a second maximum in precipitation in November-December, a problem common to many climate models in the Amazon, related to semi-annual solar forcing (Rauscher et al., 2007; Seth et al., 2007). The overall intensity of ECMWF precipitation is more comparable to the observations over NAMZ, although the amplitude of the annual cycle is too weak.

The MEX region (Fig. 1d) has a drier climate, with a weak rainy season from May to September. The model climatology agrees well with observations, except for a small wet bias $\left(\sim 1 \mathrm{~mm} \mathrm{~d}^{-1}\right)$ during the rainy season, similar to ECMWF. The wintertime wet anomaly (for NINOA) and dry anomaly (for NI$N A A$ ) over MEX are seen both in the model and observations (not shown; see TJ2009a for an example of seasonal mean anomalies). In this region, the main periods of ENSO forcing fall outside the rainy season and therefore have only a minimal impact on simulated rainfall statistics.

We discuss here the pentad-timescale El Niño anomalies shown in Figs 1e and $\mathrm{f}$. In the CAR region, the anomalous dry period of July-October (0), associated with ENSO forcing, is generally well simulated by RCA, although with slightly weaker variability than seen in the observations. RCA clearly shows a stronger and more constant dry anomaly than observed over CAR in the period May-July (0). This translates into a seasonal mean dry bias, possibly due to RCA being excessively sensitive to anomalous subsidence (for further details refer to TJ2009a). From spring $(+)$ onward, there is limited predictability associated with ENSO; as a result, there is only limited correspondence in the time evolution of the simulated and observed anomalies. It is noteworthy that RCA values generally follow more closely the GPCP observed anomalies than does the ECMWF analysed data.
Over NAMZ the documented ENSO-related dry period of July (0)-March (+) is well simulated by RCA (Fig. 1f). Similar but opposite signed anomalies in La Niña are also captured by the model (see TJ2009a for La Niña seasonal mean anomalies). The maximum observed negative anomalies are in January, the month prior to the onset of the rainy season, suggesting an important ENSO-related impact on the rainy season onset. During the rainy season, the observed anomalies are smaller, of the order of 1-2 $\mathrm{mm} \mathrm{d}^{-1}$. RCA generally captures the observed high frequency variability of precipitation, in particular the large positive and negative anomalies between January $(+)$ and July (+). This indicates the ability of a RCM to simulate subseasonal precipitation variability on the regional scale, when forced by realistic large-scale atmospheric variability and SST anomalies.

\subsection{Rainy season onset, demise and duration}

The prediction of the timing of the rainy season (onset and demise) is strongly linked to the prediction of total rainfall accumulation during the rainy season and is important in fields such as agriculture (Marengo et al., 2001). From a societal impact perspective, an accurate prediction of changes in the onset and/or demise of the rainy season may in fact be more important than an accurate prediction of seasonal mean precipitation anomalies. In this study, the rainy season onset and demise dates are calculated using the 'anomalous accumulation' method of Liebmann and Marengo (2001) using pentad mean data rather than daily data. We chose this method because it does not use a regionally defined (arbitrary) threshold of precipitation intensity (e.g. Higgins et al., 1999 and Marengo et al., 2001) and therefore should be applicable to different regions that exhibit different rainy season characteristics. The anomalous accumulation $A$ is 
defined at each grid point and each pentad as

$A(p)=\sum_{n=p_{0}}^{p}(R(n)-\bar{R})$,

where $R(n)$ is the pentad mean precipitation for pentad $n$ and $\bar{R}$ is the climatological mean pentad averaged over the entire period of the study.

For each gridpoint and each year, we start the calculation two months after the end of the climatological rainy season for that gridpoint, to account for interannual fluctuations in the demise of the rainy season. The onset and demise of each rainy season are defined, respectively, as the minimum and maximum of $A$ for each year of calculation. For each region and year, an average is calculated over all the gridpoints of the particular region.

The climatological onset and demise dates for each region, along with average dates for the El Niño and La Niña composites, are listed in Table 1. The results for individual years are shown in Fig. 2, where the relevant El Niño and La Niña years are indicated by large grey and black tick marks, respectively, along the $x$-axis. It should be noted that, for the regions CAR and CAM, the ENSO composites are computed for the years $(0)$, whereas for the NAMZ and MEX regions, the years ( + ) are used to isolate the years in the ENSO cycle where ENSO impacts are felt in each respective region. For example, in the NAMZ region the important ENSO anomalies are before the rainy season of year $(+)$, therefore we compute the timing of the rainy season during the years $(+)$ of the ENSO events.

Average results for the CAR region (Table 1) show that onset occurs during the month of May and RCA tends to show a later onset of two pentads compared with GPCP. The average demise is at the beginning of November and is well simulated. Onset and demise are shifted two weeks early in ECMWF (compared with GPCP) both on average and for individual years. The observed onset of the rainy season in years (0) is later in El Niño years and earlier in La Niña years over CAR, while RCA captures this general trend it exhibits more variability than seen in GPCP. The demise of the rainy season over CAR shows
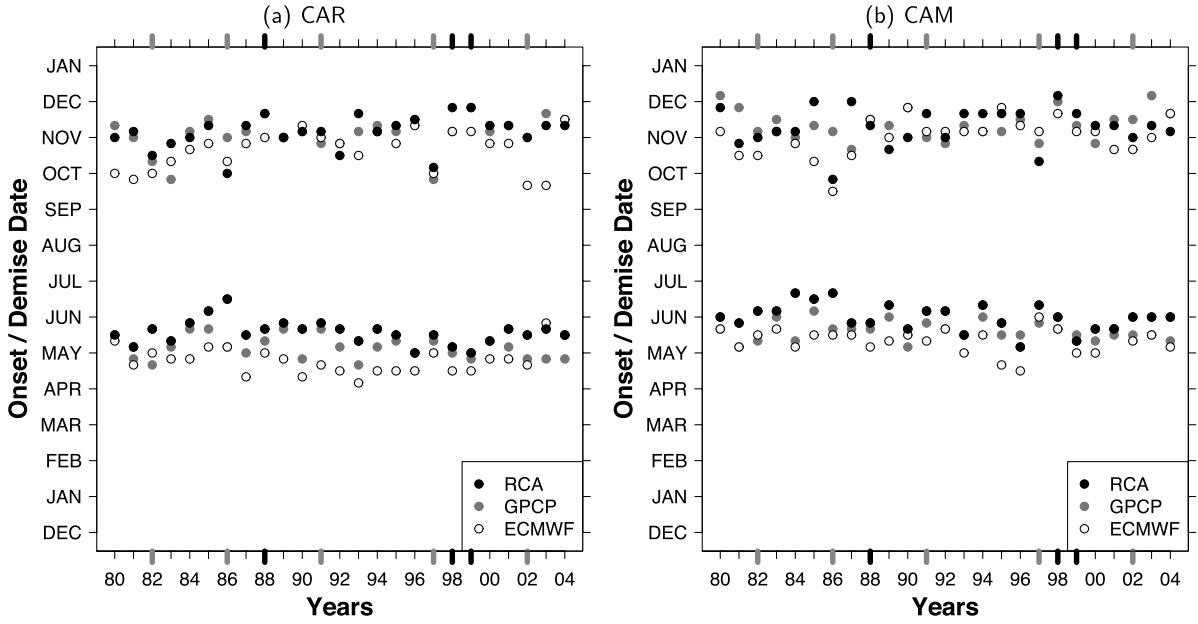

(c) NAMZ

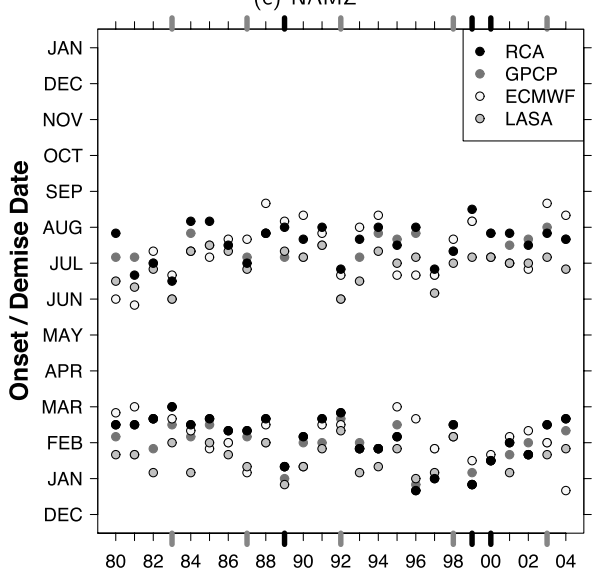

Years

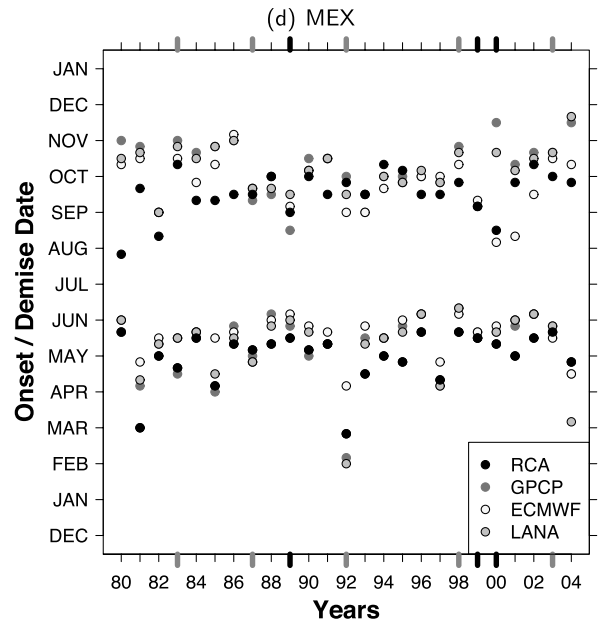

Fig. 2. Onset and demise dates of the rainy season over land by region. Where a mark is not visible, it is coincident with another mark. El Niño years are shown in large grey tick marks and La Niña years in large black tick marks on the $x$-axis. 
strong variability related to ENSO $(\approx 15 \mathrm{~d}$ early in El Niño and $\approx 15 \mathrm{~d}$ late in La Niña) for both model and observations. In Fig. 2a, the 1997 El Niño shows a shorter rainy season, most apparent in the extreme early demise $(\approx 1$ month early), which is well captured by RCA. All La Niña events (1988, 1998 and 1999) show a late demise of the rainy season over CAR, which is also generally well simulated. Values for CAM are largely similar, except that the rainy season starts three pentads later on average and the ENSO-related variability is smaller. The presence of the MSD (discussed in Section 3.1) in the CAM region, which can be seen as a series of two rainy seasons, can be challenging for the 'anomalous accumulation' method. Close inspection of time-series has shown that the technique is adequate under most circumstances, but shows a much too early rainy season demise (by a few weeks) in the extreme case of the 1986 El Niño, whereas other anomalous years (such as the 1997 El Niño) are correctly calculated.

For the NAMZ region (Table 1), rainy season onset occurs on average at the end of January, with the simulated onset in RCA delayed by one to two pentads. The demise occurs in July, and RCA shows a significantly late average date, while the length of the rainy season is well simulated; the same general conclusions also hold for ECMWF. The late onset and demise in RCA (most evident when compared to LASA) are due to deficiencies in the simulated annual cycle (Fig. 1c). The late onset in RCA over NAMZ is likely a result of the secondary (incorrect) precipitation maximum in December, leading to decreasing precipitation rates throughout January. This causes the variable $A(p)$ to continue to decrease through January and into February. In the observations, the smaller precipitation in December-January leads to the minimum in $A(p)$ being found earlier in the year. With respect to the late decay in RCA, we believe that this is related to the excessive precipitation in the model during the period April-July. This leads to the variable $A(p)$ continuing to increase through June and July, whereas the lower observed rainfall rate in this period leads to $A(p)$ reaching a maximum a few weeks earlier in the observations.

GPCP and LASA show sensitivity to ENSO forcing in the onset and demise of the rainy season of year (+) over NAMZ (late onset, early demise and shorter rainy season during El Niño events and the converse for La Niña events). The model generally captures this variability quite accurately, whereas ECMWF only shows changes in the La Niña events. The highest observed and modelled sensitivity to ENSO forcing is seen in an early onset during La Niña events (e.g. 1989 and 1999 where the onset is $\approx 1$ month early). Over NAMZ, there are some years that show a change in the rainy season onset and/or demise, which are not associated with ENSO forcing, in both model and observations (e.g. 1996). This is likely related to changes in Atlantic SSTs, independent of ENSO variability, which have a coherent impact on moisture convergence and rainy season onset over NAMZ. As RCA uses observed SSTs and analysed LBCs any coherent forcing from Atlantic SST anomalies will likely be available to the model. It is noteworthy that ECMWF analysed precipitation does not show an early onset in 1996, in disagreement with both observation data sets.

In the MEX region (Table 1), rainy season onset occurs at the beginning of May. RCA shows a slightly earlier onset on average compared with observations. The demise occurs on average at the beginning of October for the observations, but four pentads earlier for RCA. This is consistent with the annual cycle results (see Fig. 1d), where a sharp drop in the simulated precipitation is seen in mid-September. The biases in onset and demise (also seen in Fig. 2d) exhibit significant year-to-year variability and result in a shorter rainy season for RCA and ECMWF on average. Although the match between model and observations in this region is the weakest, RCA does capture some of the ENSOrelated variability in the timing of the rainy season. As the main ENSO forced precipitation anomalies occur during the winter season, hence outside of the rainy season, we would expect less predictability in the changes in the timing of the rainy season. There is, however, a general tendency towards early onset/late demise in the rainy season of years (+) of the El Niño composites, and the converse for La Niña years, which is well captured by the model.

\subsection{Intensity distribution of precipitation}

An accurate prediction of precipitation intensity distribution is important in fields such as water management and agriculture (Seth et al., 2004), where the distribution of rainfall intensity is at least as important as the seasonal mean value.

3.3.1. Histograms by region. Pentad-mean intensity distributions are evaluated during the rainy season of each of the four regions. As was shown earlier, there is considerable interannual variability in the onset, demise and length of the rainy season in each region. Much (but not all) of this variability is associated with ENSO forcing. Our goal is to evaluate the changes in the intensity distribution during the rainy season associated with ENSO forcing, independent of the changes in the timing of the rainy season. To do this, for each individual year and each region, we compute precipitation intensity distributions within the onset and demise dates of the rainy season for that particular year (the calculation of which follows the method described in the previous section). This is done for model and observations separately. In doing so, we evaluate if the shifts in the distribution are primarily attributable to changes within the rainy season of each year or rather to changes in the duration of the rainy season.

Figure 3 shows the area-averaged precipitation intensity distribution binned into six categories for each of the four regions, averaged over each of the (variable-length) rainy seasons. The first three bins $\left(0-1,1-2.5\right.$ and $\left.2.5-5 \mathrm{~mm} \mathrm{~d}^{-1}\right)$ are considered light, the intermediate bin $\left(5-10 \mathrm{~mm} \mathrm{~d}^{-1}\right)$ moderate and the last two bins (10-20 and $20+\mathrm{mm} \mathrm{d}^{-1}$ ) intense precipitation events. The top row shows the climatological average of the distribution 
(a) CAR / CLIM

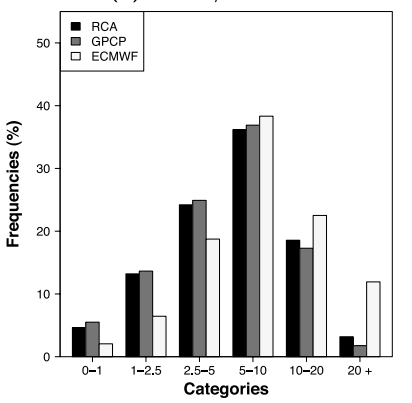

(e) CAR / CLIM accum.

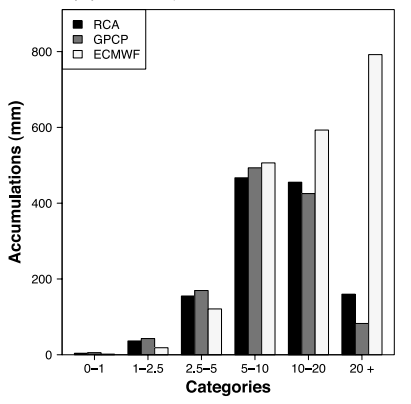

(i) CAR / NINOA

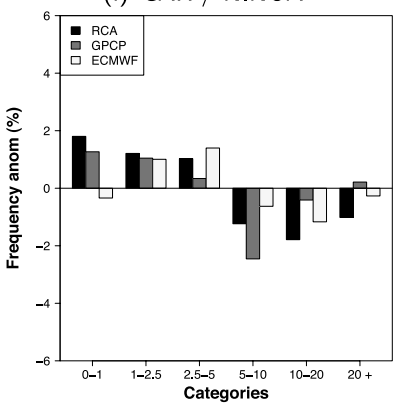

(m) CAR / NINAA

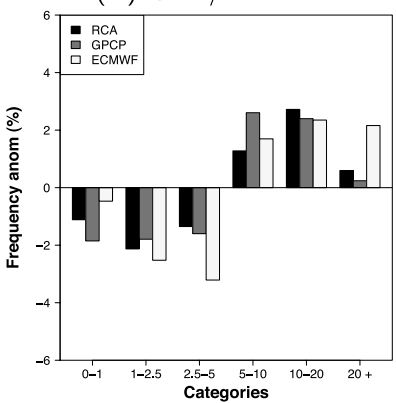

(b) CAM / CLIM

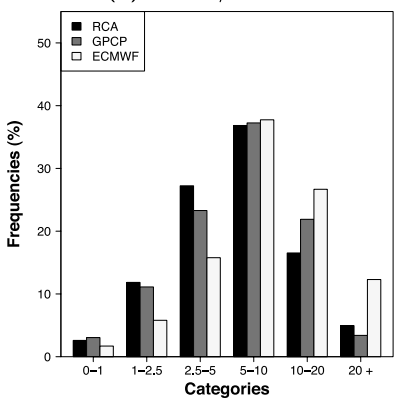

(f) CAM / CLIM accum.

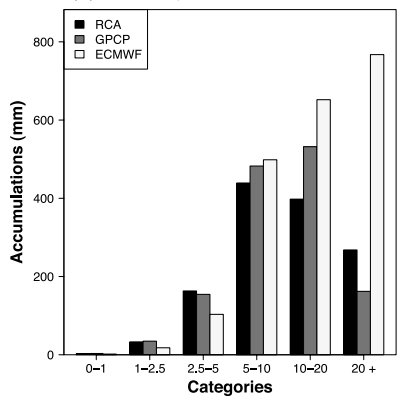

(j) CAM / NINOA

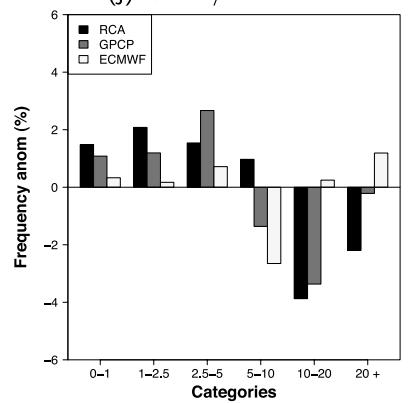

(n) CAM / NINAA

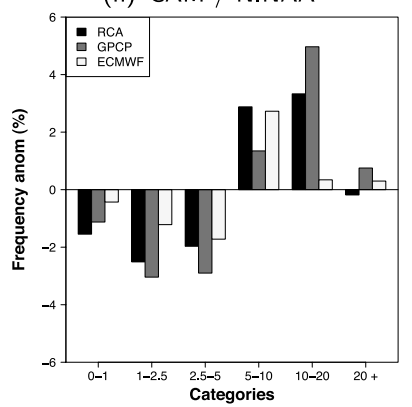

(c) NAMZ / CLIM

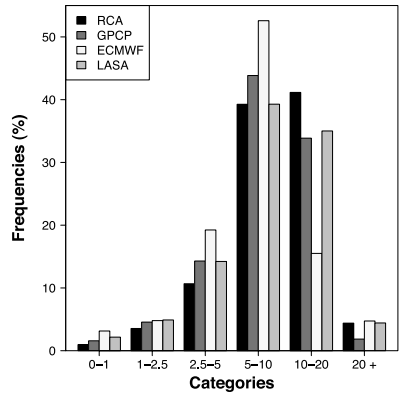

(g) NAMZ / CLIM accum.

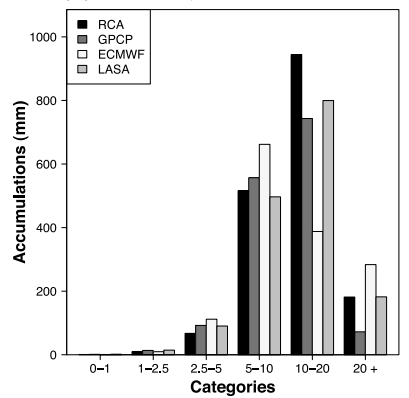

(k) NAMZ / NINOA

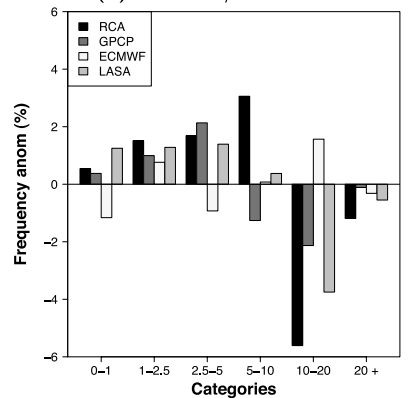

(o) NAMZ / NINAA

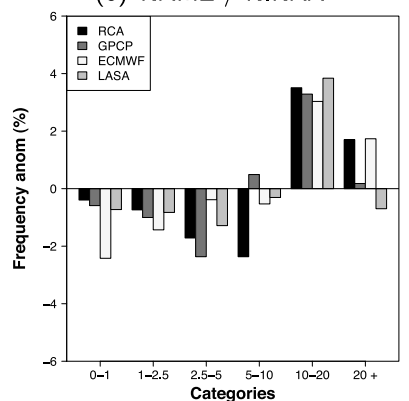

(d) MEX / CLIM

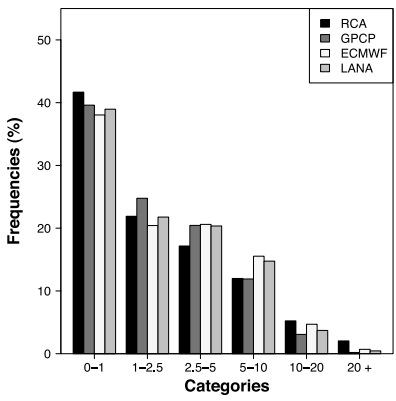

(h) MEX / CLIM accum.

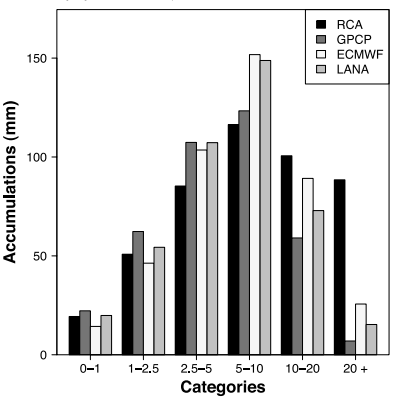

(I) MEX / NINOA

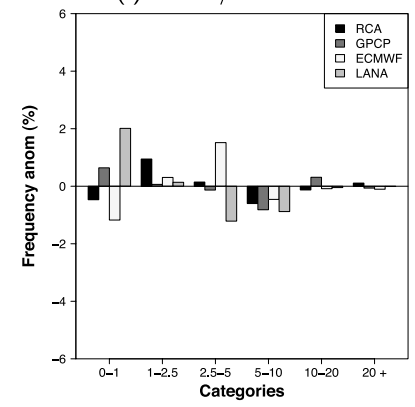

(p) MEX / NINAA

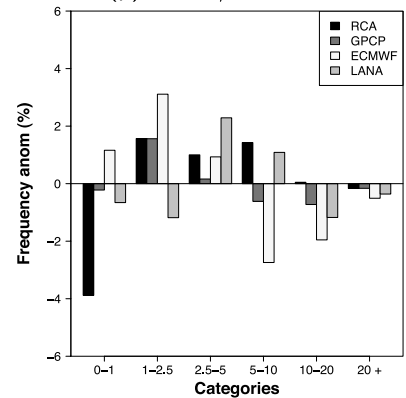

Fig. 3. Precipitation intensity distribution (percent of pentads) over land during yearly computed rainy seasons/climatological frequency of occurrence (top row), climatological accumulated precipitation for each intensity bin (middle row) and anomalies in binned frequency of occurrence for El Niño and La Niña years (bottom rows)/regions CAR, CAM, NAMZ and MEX (columns). The scales on the $y$-axis are different in each plot.

in terms of percentage of frequency of occurrence, the second row shows the accumulated precipitation emanating from each intensity bin during the period of calculation, whereas the lower rows show the anomalies in the frequency of occurrence of each intensity class, averaged over the strong El Niño (NINOA) and
La Niña (NINOA) years, respectively. As in the onset calculations, the years used for the ENSO anomalies are the years (0) for CAM and CAR, and years (+) for NAMZ and MEX, these being the years when ENSO forcing is maximum in the respective regions. 
In the CAR region (Figs 3a, e, i and $\mathrm{m}$ ), the climatological intensity distribution of precipitation during the rainy season is well simulated by RCA, except for a small under-estimate in the $5-10 \mathrm{~mm} \mathrm{~d}^{-1}$ category and a small overestimate in the $20+\mathrm{mm} \mathrm{d}^{-1}$ category, the latter of which is responsible for the small positive bias in the annual cycle. ECMWF shows large underestimates in the low-intensity categories and overestimate in the high-intensity categories, consistent with the large wet bias seen in Fig. 1a. Anomalies during ENSO years over CAR do show a small shift $(\approx 1 \%$ in each category), with more light precipitation events and less moderate and intense precipitation events. The converse is true for La Niña events, but the anomalies are of greater magnitude $(\approx 1-2 \%$ change in each category). The model reproduces most of the observed variability, with some deviations in the intense categories. The biases in the tail ends of the distribution in El Niño events explain the dry bias seen in May-July (0) NINOA of the annual cycle (see Fig. 1e).

Over the CAM region (Figs $3 b, f, j$ and $n$ ), the simulated distribution is not as accurate as in the CAR region, although the modal intensity $\left(5-10 \mathrm{~mm} \mathrm{~d}^{-1}\right)$ is the same as in the observations and biases are less than $5 \%$ in each category. The anomalies related to ENSO are similar to those in the CAR region but of larger magnitude. RCA again captures the overall shift in the distribution, as over CAR, but there is an excessive reduction in the frequency of very intense $\left(20+\mathrm{mm} \mathrm{d}^{-1}\right)$ precipitation pentads. In most categories, the model is more accurate than ECMWF (relative to GPCP).

The NAMZ region (Figs 3c, g, k and o) has a more bimodal distribution, with most occurrences $(\approx 75 \%)$ in the $5-20 \mathrm{~mm} \mathrm{~d}^{-1}$ range. RCA shows good agreement with observations, except in the two categories 5-10 and $10-20 \mathrm{~mm} \mathrm{~d}^{-1}$, with an underestimate in the former balanced by an overestimate (in frequency) in the latter, explaining the wet bias in the second half of the rainy season. In ECMWF, although the pentad-mean precipitation is reasonable in the rainy season, the 5-10 and $10-20 \mathrm{~mm} \mathrm{~d}^{-1}$ categories are not well represented. As in the two previous regions, the ENSO-related anomalies are clear and relatively well simulated.

To show the effect of using an interannually varying rainy season duration for the period of analysis, compared with using a fixed climatological rainy season, we plot the precipitation intensity distribution for the NAMZ region for a fixed rainy season, February-June, in Figs 4a, c, e and g. The climatological distribution is generally similar but shows a shift towards lighter precipitation events due to the increased inclusion of dry days in the distribution during years when the rainy season is delayed. The ENSO related shifts in the distribution are larger (by a factor of almost 2) compared with the previously discussed results. RCA simulates most of the anomalies but again shows some discrepancies mainly in the $5-10$ and $20+\mathrm{mm} \mathrm{d}^{-1}$ categories. As the variability is greater using this method, we conclude that the variability in the intensity distribution in the rainy season
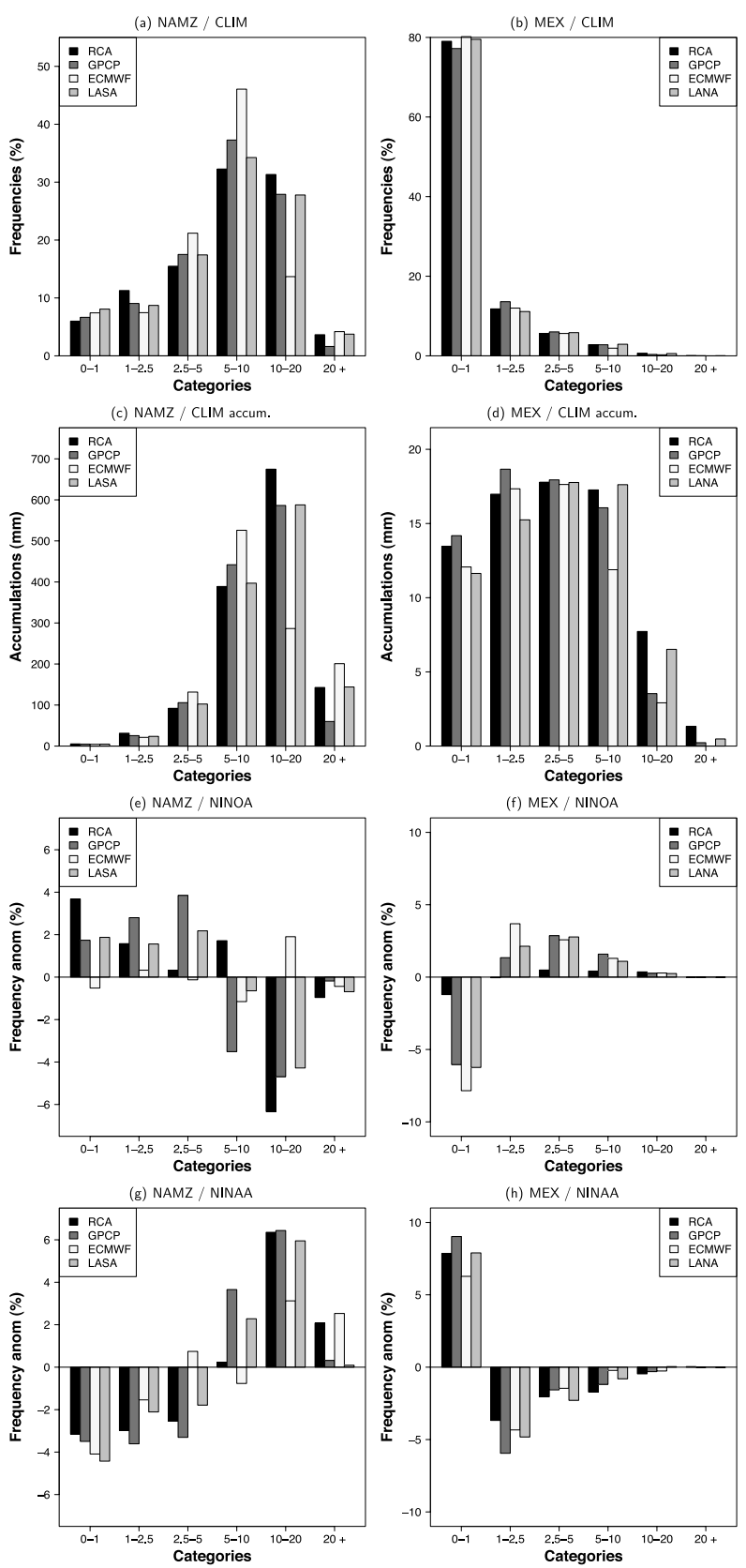

Fig. 4. As Fig. 3 but for NAMZ region using a fixed rainy season February-July (left-hand column) and MEX region using a fixed dry season January-March (right-hand column).

over NAMZ is due to both changes in the timing (onset and demise) of the rainy season, as well as changes in the distribution within the (interannually variable) rainy season. Over the CAR and CAM regions, the two methods show similar anomalies (not shown); therefore in these regions, we conclude that changes in the intensity distribution are mostly due to changes within the rainy season and not changes in the timing. 
The final region, MEX (Figs 3d, h, 1 and p), having a much drier climate, has an observed and modelled modal intensity in the no-rain $\left(0-1 \mathrm{~mm} \mathrm{~d}^{-1}\right)$ category. The model shows a small bias towards more dry, less moderate and more extreme events. With regard to changes in the intensity distribution associated with ENSO, our results show no clear signal, which should be expected recalling that the main documented ENSO impact occurs in October (0)-March (+), outside of the rainy season in MEX. In this region, ECMWF results are comparable to observations.

As the ENSO-related variability in the MEX region is primarily in the dry season, we show in Figs $4 \mathrm{~b}, \mathrm{~d}$, $\mathrm{f}$ and $\mathrm{h}$ the intensity distribution during January-March and the anomalies in the same months for years (+) of the ENSO events. The modal intensity is still in the dry $\left(0-1 \mathrm{~mm} \mathrm{~d}^{-1}\right)$ category, but with a much larger intensity of $\approx 70 \%$. All categories are well simulated by RCA. The anomalies in the El Niño years are now apparent (although marginally in RCA), with a shift towards fewer no-rain events and more events in the $2.5-20 \mathrm{~mm} \mathrm{~d}^{-1}$ range, accounting for a wetter dry season. In the La Niña years, the shift is more dramatic and better captured by the model. As there are more consistent anomalies associated with ENSO (compared with Fig. 3), we conclude that ENSO has an impact on the intensity distribution of precipitation during the dry season only.
The limited temporal extent of high-resolution pentad (and daily) data sets such as TRMM is the main reason that GPCP was used as the primary observational data set in this study. This limits the assessment of the benefits accruing from the increased resolution of a RCM. Here we briefly present results for the 1998-2004 period, comparing the $0.33^{\circ}$ version of RCA to a lower-resolution version of the model run at $1.0^{\circ}$ (RCA1), as well as high-resolution TRMM and low-resolution GPGP as reference (all interpolated to a $1^{\circ}$ grid). Figure 5 shows the climatological frequency of occurrence and accumulated precipitation for each intensity bin for regions CAR and NAMZ only during their respective rainy season. In most cases, RCA is closer to both TRMM and GPCP than the lower-resolution simulation RCA1. For example, RCA1 is the clear outlier in the 5-10 and $20+\mathrm{mm} \mathrm{d}^{-1}$ categories for both regions. RCA1 shows excessive frequency and accumulation in the $20+\mathrm{mm} \mathrm{d}^{-1}$ category, similar to ECMWF (Figs 3a, b, e and f). It is worth noting here that the model used in generating the ERA-40/ECMWF analysis data set used in this study has a resolution comparable to RCA1. The high-resolution TRMM and lower-resolution GPCP are in general accordance when spatially averaged. This is even more evident when looking at the accumulation plots, with differences of less than $100 \mathrm{~mm}$ in each category. These points lead to the following conclusions: (1) RCA is more realistic at $0.33^{\circ}$
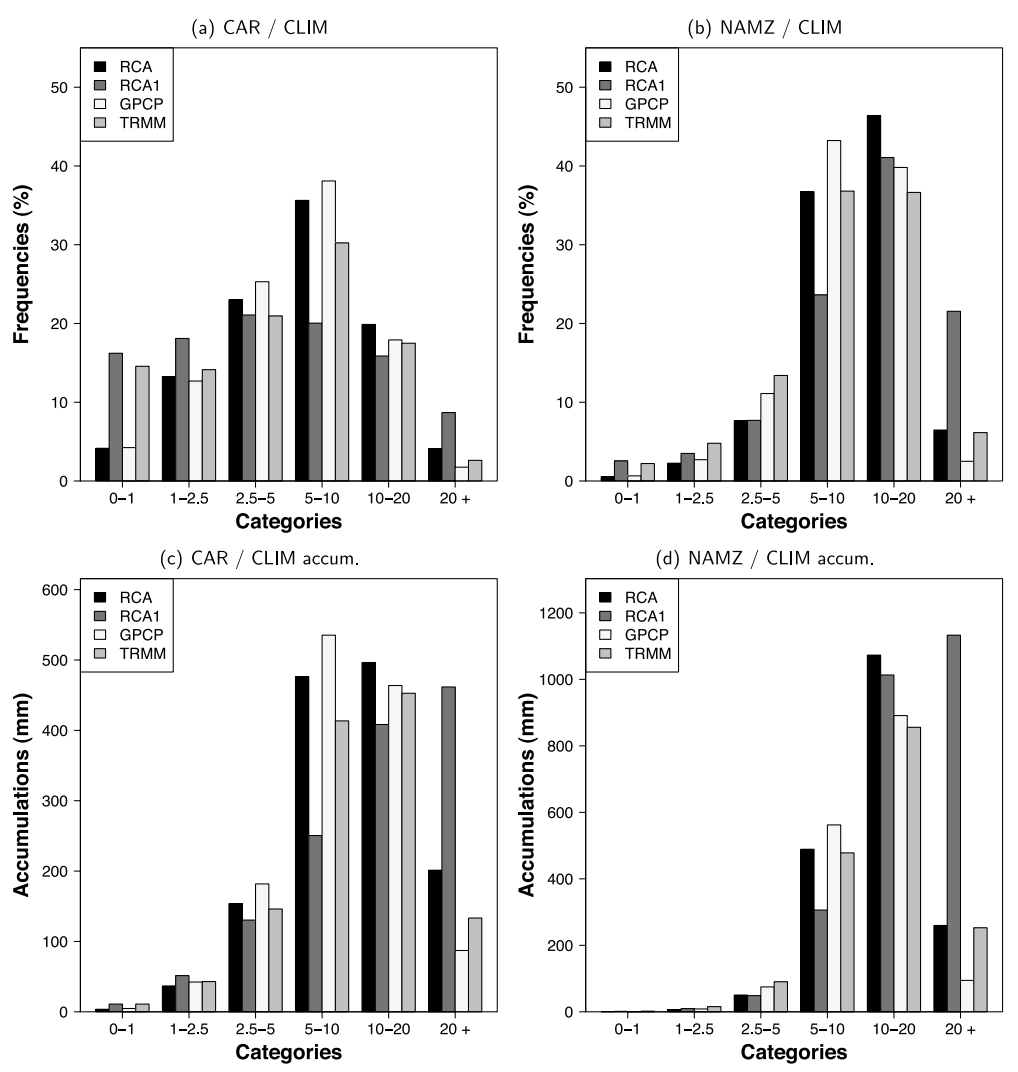

Fig. 5. Precipitation intensity distribution (percent of pentads) over land during yearly computed rainy seasons during the 1998-2004 period/climatological frequency of occurrence (top row), climatological accumulated precipitation for each intensity bin (bottom row)/regions CAR and NAMZ (left- and right-hand columns, respectively). The scales on the $y$-axis are different in each plot. 
(a) GPCP / CLIM

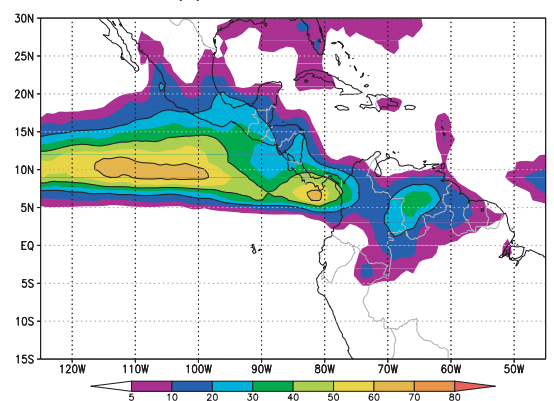

(d) GPCP / NINOA

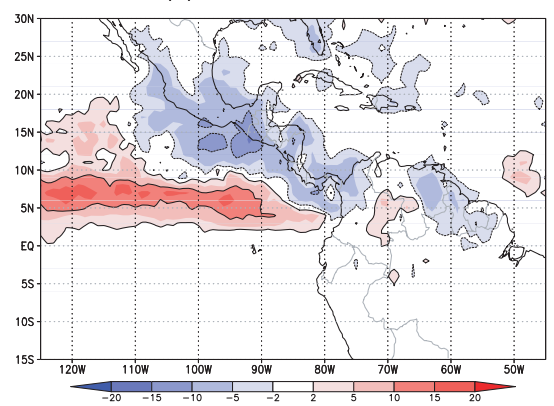

(g) GPCP / NINAA

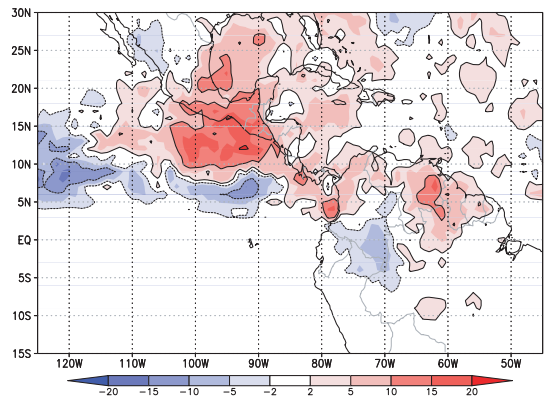

(b) ECMWF / CLIM

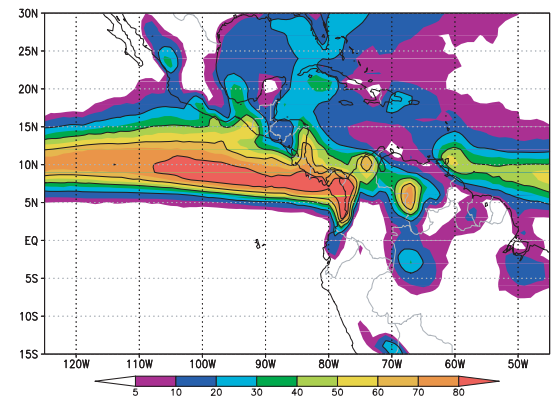

(e) ECMWF / NINOA

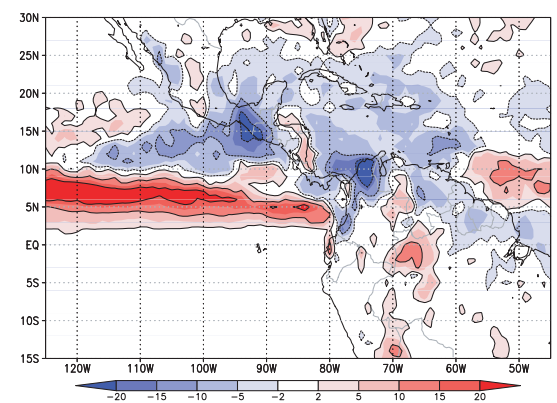

(h) ECMWF / NINAA

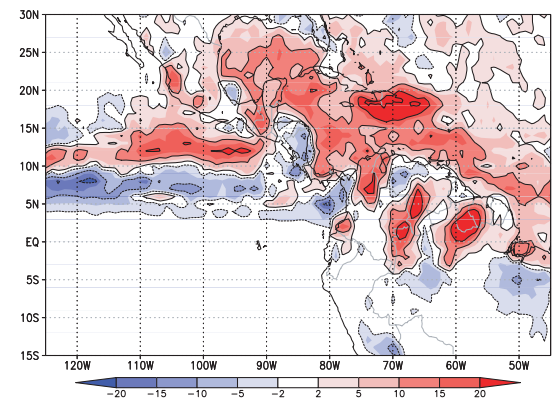

(c) RCA / CLIM

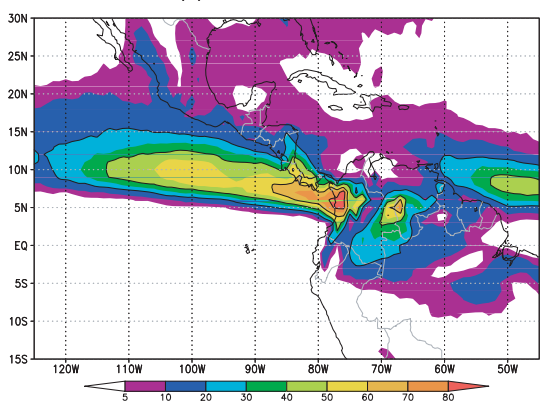

(f) RCA / NINOA

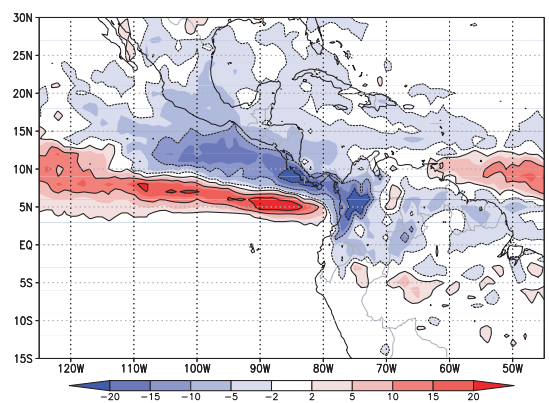

(i) RCA / NINAA

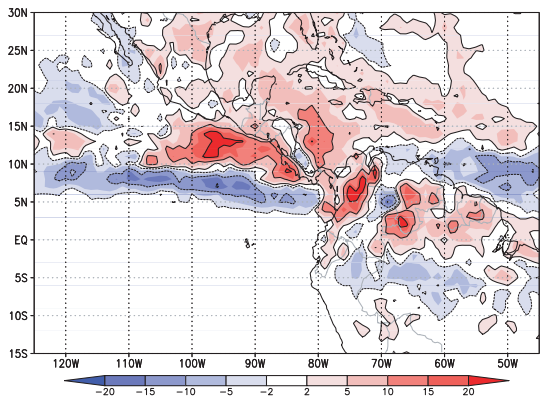

Fig. 6. Frequency of occurrence of pentad-mean precipitation in excess of $10 \mathrm{~mm} \mathrm{~d}^{-1}$ (in percent of total precipitation intensity occurrence) for June-September/GPCP, ECMWF and RCA (columns)/Climatology (top row), El Niño anomalies (NINOA) during JAS(0) season (middle row) and La Niña anomalies (NINAA) during JAS(0) season (bottom row), respectively.

than $1.0^{\circ}$ in simulating the precipitation intensity distribution; (2) GPCP pentad data at $2.5^{\circ}$ resolution are reliable enough to be used as an observational surrogate for comparison with highresolution data, when spatially averaged over relatively small regions, and (3) RCA1 and ECMWF both have a tendency to overestimate the frequency of intense precipitation in regions CAR and NAMZ.

3.3.2. Spatial maps of precipitation intensity. As a final evaluation of RCA's ability to simulate the intensity distribution of precipitation and its changes due to ENSO forcing, we plot spatial maps showing the occurrences of pentad-mean precipitation intensity greater than $10 \mathrm{~mm} \mathrm{~d}^{-1}$ (intense precipitation events), along with changes in the occurrence of these events, expressed as deviations in percent from the climatological occurrence, for El Niño and La Niña years separately. Figure 6 emphasizes the rainy season in the northern portion of the do- main, with the top row showing climatological results during the fixed July-September months and the two bottom rows showing the NINOA and NINAA of above $10 \mathrm{~mm} \mathrm{~d}^{-1}$ occurrences for the months July-September (0), when anomalies are important in Central America and the Caribbean. The columns show, in order, GPCP, ECMWF and RCA. We also show in Fig. 7 the climatological values for the shorter 1998-2004 period for RCA, RCA1, GPCP and TRMM as an additional high-resolution comparison.

In the climatological mean for the 1979-2004 period (Figs $6 a-c)$, we clearly see the location of the ITCZ, around $10^{\circ} \mathrm{N}$, with over $40 \%$ of the total rainfall coming from pentadmean rainfall rates greater than $10 \mathrm{~mm} \mathrm{~d}^{-1}$. RCA has a slight eastward shift in the East Pacific and an enhanced ITCZ in the Atlantic, similar to the seasonal averages compared with the monthly GPCP data set (see TJ2009a). The East Pacific ITCZ is severely over-estimated in ECMWF, and somewhat in the west 
(a) GPCP

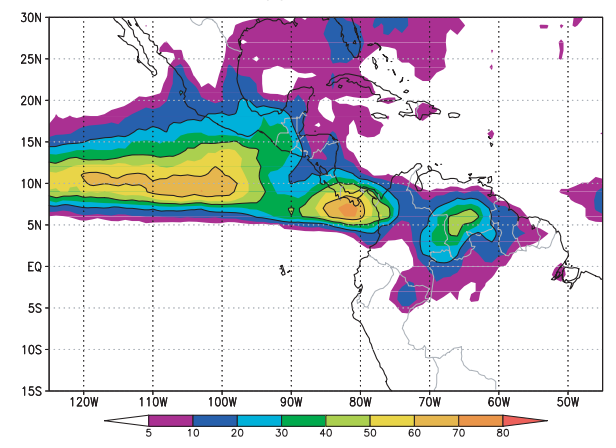

(c) RCA

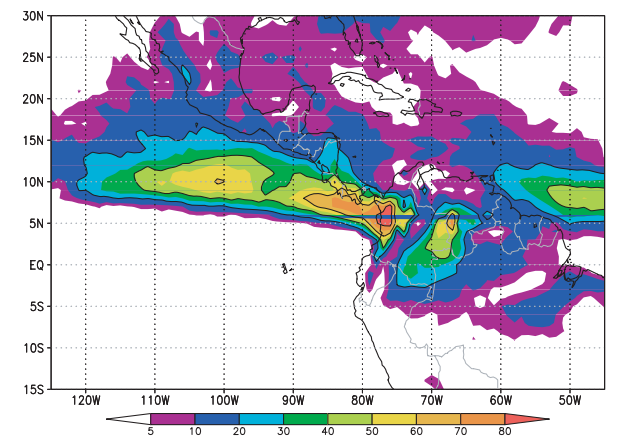

(b) TRMM

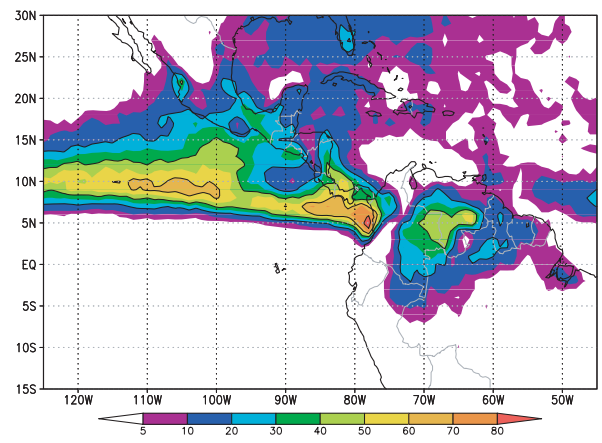

(d) RCA1

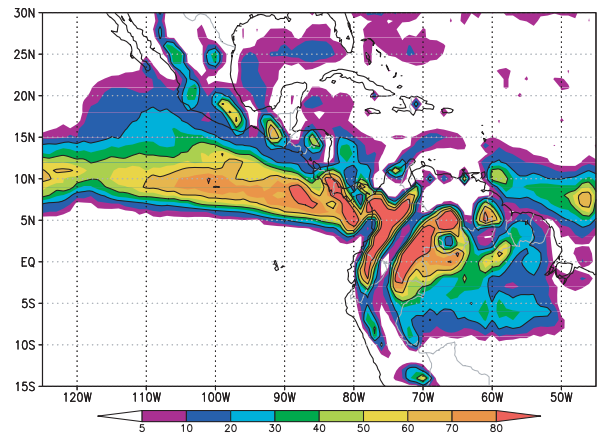

Fig. 7. Frequency of occurrence of pentad-mean precipitation in excess of $10 \mathrm{~mm} \mathrm{~d}^{-1}$ (in percent of total precipitation intensity occurrence) for June-September during the 1998-2004 period.

Atlantic. Both RCA and ECMWF show the same overestimate of intense precipitation occurrence (compared with GPCP) in the tropical west Atlantic. This is close to the lateral boundary in RCA, where the model is relaxed towards the ECMWF driving atmospheric fields. The commonality of RCA and ECMWF precipitation in this region may therefore be a result of errors in the atmospheric and dynamical forcing in the ECMWF analyses. RCA also shows more occurrences $(\approx 5-10 \%)$ of intense precipitation events in the Caribbean and Gulf of Mexico when compared with GPCP, consistent with the wet bias in the seasonal cycle. The higher occurrence of intense precipitation in this region is, however, more consistent with the TRMM data set for the period 1998-2004 (see Fig. 7). The lower-resolution model RCA1 also exhibits an excessive East Pacific ITCZ in the 1998-2004 period, similar to ECMWF (Figs 6b and 7d). There is also a clear positive bias in orographically forced rainfall in RCA1 (clearly seen in northern South America, Fig. 7d), predominantly related to high-intensity precipitation classes (as seen in Fig. 5). We believe that this is linked to problems with an accurate representation of resolved scale vertical velocity over mountainous regions and its role in the Kain-Fritsch convective trigger function (further explanation is given in section 5 of TJ2009a). Over northern South America, RCA shows a small positive frequency bias $(\approx 10-20 \%)$ compared with both GPCP and TRMM, which is consistent with the wet bias in the annual cycle and positive bias in the $10+\mathrm{mm} \mathrm{d}^{-1}$ intensity categories over the NAMZ region.
Looking at the NINOA of the intense precipitation events (Figs 6d-f), the spatial structure and magnitude of the anomalies are generally well simulated. The southern half of the East Pacific ITCZ shows a positive anomaly of $20 \%$ (i.e. $20 \%$ more occurences of precipitation $>10 \mathrm{~mm} \mathrm{~d}^{-1}$ ). Most regions north of this exhibit a negative anomaly of $10 \%$ on average (attributable to changes in the Hadley circulation). Both the RCA and ECMWF anomalies in this region are generally of the correct sign, but larger than the GPCP values. There are small negative anomalies in northern South America. Anomalies are slightly exaggerated in RCA and ECMWF over the Caribbean, Central America and northern Mexico.

The NINAA plots (Figs 6g-i) show almost inverse anomalies. In the tropical East Pacific and Atlantic Oceans, negative anomalies are greater and more widespread in RCA than in GPCP. The weakened descending branch of the Hadley circulation (mostly over Mexico and the Caribbean) leads to positive rainfall anomalies of $+10-20 \%$ during La Niña years. Positive anomalies are slightly overestimated over the Caribbean in RCA, whereas there is a severe overestimate in ECMWF (also seen in the histograms for the CAR region in Fig. 3m). Northeast South America, and parts of the NAMZ domain, see a positive anomaly of $\approx 10 \%$ corresponding to changes in the Walker circulation during La Niña events, whereas regions south of that show a negative anomaly of $\approx 5 \%$, which, while captured, is more widespread in RCA. RCA shows a distinctive rainshadow effect on the eastern slope of the Andes, which is marginally seen in the observations. 


\section{Discussion and conclusions}

We have evaluated the performance of RCA in simulating subseasonal statistics of pentad-mean precipitation, in particular the interannual variability of pentad-mean rainfall associated with ENSO forcing. The annual cycle is well simulated by the model, except for a wet bias starting in the middle of the observed rainy season over the northern Amazon. Anomalies associated with ENSO are also generally well simulated in the four regions analysed, at least during the periods of well-known ENSO forcing. There are a few exceptions to this, notably before the onset of the rainy season in Central America and the Caribbean, where RCA shows excessive dry conditions in El Niño years and the converse in La Niña years.

The timing of the rainy season (onset, demise and duration) is found to be well simulated by the model, with biases of usually less than two weeks. One problem is found in the northern Amazon, where the model shows a later onset and demise of the rainy season due to a general wet bias and double maxima in the annual cycle of precipitation. Over the MEX region the demise of the rainy season is 3 weeks early in RCA compared with observations. One of the main changes induced by ENSO is an early/late demise in the rainy season over Central America and the Caribbean for El Niño/La Niña year (0), respectively. Northern Amazon experiences a late/early onset of the rainy season for El Niño/La Niña years (+), respectively, and to a lesser extent an early/late demise. In these latter three regions (CAR, CAM and NAMZ), the duration of the rainy season is shorter/longer in the relevant El Niño/La Niña years, due to changes in the onset and demise dates. Over the MEX region there is an early demise in the years (+) of La Niña events and an early/late onset during El Niño/La Niña years, respectively, consistent with wet/dry anomalies during the dry season. These changes in the timing result in a longer/shorter rainy season in El Niño/La Niña years $(+)$. All of these modulations in the timing of the rainy season associated with ENSO forcing are generally well captured by RCA.

The climatological, pentad-mean intensity distribution of precipitation during the rainy season is generally well simulated by the model, although a model wet bias over northern Amazon is associated with an overestimate in the frequency of intense precipitation events $\left(10+\mathrm{mm} \mathrm{d}^{-1}\right)$. Overall, RCA adequately simulates the documented anomalies in rainfall intensity associated with ENSO forcing. The periods when the model disagrees with observations generally lie outside of these strongly forced periods, when predictability is limited. Seasonal mean dry anomalies are associated with a shift in the pentad-mean intensity distribution, with an increased frequency of light intensity events and a decreased frequency of intense events, the converse is true for wet seasonal anomalies. Over the northern Amazon, ENSO induces both changes in the timing of the rainy season as well as changes in the intensity distribution within the shorter/longer rainy season. Over Central America and the Caribbean, changes are mainly in the distribution within the rainy season, whereas changes in the rainy season length are less important. Finally, changes in the intensity distribution over MEX are only seen in the dry season, this being the period when ENSO anomalies have a impact over this region.

In the two parts of this study, we have evaluated the ability of RCA to downscale SST and large-scale atmospheric anomalies over the tropical Americas associated with ENSO variability, when RCA is forced by observed SST and analysed LBCs. This has been done both for seasonal mean precipitation and subseasonal (pentad) rainfall. We have found that RCA offers a downscaling improvement over the driving LBC data (ECMWF) in terms of precipitation, and that the high resolution of $0.33^{\circ}$ offers more realistic results than a lower-resolution version (at $1.0^{\circ}$ ). These first results are encouraging in the context of downscaling accurate large-scale circulation anomalies. Further work in this area will involve running RCA with lateral boundary forcing obtained from a suite of GCM hindcasts to assess the combined ability of a GCM-RCM couplet to simulate regional-scale interannual variability of precipitation over the tropical Americas.

\section{Acknowledgments}

We wish to thank the Servicio Meteorológico Nacional de México for generously providing station precipitation observations for Mexico. The U.S. precipitation data are from the US Cooperative Observing Network and were obtained from the National Climatic Data Center. We also thank Dave Allured and Brant Liebmann for preparing and providing the gridded data set for daily precipitation over North America and Sara A. Rauscher for her insight and suggestions. We also acknowledge the assistance of Anders Ullerstig and Patrick Samuelsson of the Rossby Centre at the Swedish Meteorological and Hydrological Institute (SMHI) in preparing the lateral and surface boundary conditions used to force RCA.

The RCA integrations were performed at the National Supercomputer Centre in Linköping, Sweden. This research was funded by CLIVAR grant 201649, NSERC grant RGPIN/327250-2006, CFCAS grant NW CRCMD and Ouranos Inc. ECMWF ERA-40 data used in this study have been provided by ECMWF.

\section{References}

Alexander, M. A., Blade, I., Newman, M., Lanzante, J. R., Lau, N.-C. and co-authors. 2002. The atmospheric bridge: the influence of ENSO Teleconnections on air-sea interaction over the global oceans. J. Climate 15, 2205-2231.

Enfield, D. B. and Alfaro, E. J. 1999. The dependence of Caribbean rainfall on the interaction of the tropical Atlantic and Pacific Oceans. J. Climate 12, 2093-2103.

Fu, R., Dickinson, R. E., Chen, M. and Wang, H. 2001. How do tropical sea surface temperatures influence the seasonal distribution of precipitation in the equatorial Amazon?. J. Climate 14, 4003-4026. 
Goddard, L., Mason, S. J., Zebiak, S. E., Ropelewski, C., Basher, R. and co-authors. 2001. Current approaches to seasonal to interannual climate predictions. Int. J. Climatol. 21, 1111-1152.

Higgins, R. W., Chen, Y. and Douglas, A. V. 1999. Interannual variability of the North American warm season precipitation regime. J. Climate 12, 653-680.

Huffman, G. J., Adler, R. F., Morrissey, M. M., Bolvin, D. T., Curtis, S. and co-authors. 2001. Global precipitation at one-degree daily resolution from multisatellite observations. J. Hydrometeorol. 2, 3650 .

Huffman, G. J., Adler, R. F., Bolvin, D. T., Gu, G., Nelkin, E. J. and co-authors. 2007. The TRMM multisatellite precipitation analysis (TMPA): quasi-global, multiyear, combined-sensor precipitation estimates at fine scales. J. Hydrometeorol. 8, 38-55.

Jones, C. G., Willén, U., Ullerstig, A. and Hansson, U. 2004. The Rossby Centre Regional Atmospheric Climate Model part I: model climatology and performance for the present climate over Europe. Ambio 33, 199-210.

Kjellström, E., Bärring, L., Gollvik, S., Hansson, U., Jones, C. and co-authors. 2005. A 140-year simulation of European climate with the new version of the Rossby Centre regional atmospheric climate model (RCA3). SMHI Reports Meteorology and Climatology 108. SMHI, SE-60176 Norrköping, Sweden, 54 pp.

Liebmann, B. and Allured, D. 2005. Daily precipitation grids for South America. Bull. Am. Meteorol. Soc. 86, 1567-1570.

Liebmann, B. and Marengo, J. A. 2001. Interannual variability of the rainy season and rainfall in the Brazilian Amazon basin. J. Climate 14, 4308-4318.

Marengo, J. A. 1992. Interannual variability of surface climate in the Amazon basin. Int. J. Climatol. 12, 853-863.

Marengo, J. A. and Hastenrath, S. 1993. Case studies of extreme climatic events in the Amazon basin. J. Climate 6, 617-627.

Marengo, J. A., Liebmann, B., Kousky, V. E., Filizola, N. P. and Wainer, I. C. 2001. Onset and end of the rainy season in the Brazilian Amazon basin. J. Climate 14, 833-852.

Nobre, P. and Shukla, J. 1996. Variations of sea surface temperature, wind stress, and rainfall over the tropical Atlantic and South America. J. Climate 9, 2464-2479.

Rauscher, S. A., Seth, A., Liebmann, B., Qian, J.-H. and Camargo, S. J. 2007. Regional climate model-simulated timing and character of seasonal rains in South America. Mon. Wea. Rev. 135, 2642-2657.
Ropelewski, C. F. and Bell, M. A. 2008. Shifts in the statistics of daily rainfall in South America conditional on ENSO phase. J. Climate 21, 849-865.

Ropelewski, C. F. and Halpert, M. S. 1987. Global and regional scale precipitation patterns associated with the El Niño/Southern Oscillation. Mon. Wea. Rev. 115, 1606-1626.

Ropelewski, C. F. and Halpert, M. S. 1989. Precipitation patterns associated with the high index phase of the southern oscillation. J. Climate 2, 268-284.

Ropelewski, C. F. and Halpert, M. S. 1996. Quantifying Southern Ocillation-precipitation relationships. J. Climate 9, 10431059.

Seth, A., Rojas, M., Liebmann, B. and Qian, J.-H. 2004. Daily rainfall analysis for South America from a regional climate model and station observations. Geophys. Res. Lett. 31, L07213.

Seth, A., Rauscher, S. A., Camargo, S. J., Qian, J.-H. and Pal, J. S. 2007. RegCM3 regional climatologies for South America using reanalysis and ECHAM global model driving fields. Climate Dyn. 28, 461380.

Small, R. J. O., de Szoeke, S. P. and Xie, S.-P. 2007. The Central American midsummer drought: regional aspects and large-scale forcing. J. Climate 20, 4853-4873.

Sun, L., Moncunill, D. F., Li, H., Moura, A. D., Filho, F. D. A. D. S. and co-authors. 2006. An operational dynamical downscaling prediction system for Nordeste Brazil and the 2002-04 real-time forecast evaluation. J. Climate 19, 1990-2007.

Tourigny, E. and Jones, C. 2009. An analysis of regional climate model performance over the tropical Americas. Part I: simulating seasonal variability of precipitation associated with ENSO forcing. Tellus A, doi:10.1111/j.1600-0870.2008.00386.x.

Uppala, S. M., Kållberg, P. W., Simmons, A. J., Andrae, U., da Costa Bechtold, V. and co-authors. 2005. The ERA-40 re-analysis. Quart. J. R. Meteor. Soc. 131, 2961-3012.

Wang, H.-J., Zhang, R.-H., Cole, J. and Chavez, F. 1999. El Niño and the related phenomenon Southern Oscillation (ENSO): the largest signal in interannual climate variation. Proc. Natl. Acad. Sci. USA 96(20), 11071-11072.

Xie, P., Janowiak, J. E., Arkin, P. A., Adler, R., Gruber, A. and coauthors. 2003. GPCP pentad precipitation analyses: an experimental dataset based on gauge observations and satellite estimates. J. Climate 16, 2197-2214. 